Témoigner Témoigner. Entre histoire et mémoire

Getuigen Revue pluridisciplinaire de la Fondation Auschwitz

$124 \mid 2017$

La musique dans les camps

\title{
Reisverslag. Op zoek naar de misdaden van de rode Khmers: de cambodjaanse herinneringsplekken
}

Carnet de voyage: sur les traces des crimes des Khmers rouges découverte et description de «lieux» de mémoire cambodgiens

Mélanie Moreas

Traducteur : Gorik de Henau

\section{(2) OpenEdition}

Journals

Édition électronique

URL : https://journals.openedition.org/temoigner/5950

DOI : $10.4000 /$ temoigner.5950

ISSN : 2506-6390

Éditeur :

Éditions du Centre d'études et de documentation Mémoire d'Auschwitz, Éditions Kimé

Édition imprimée

Date de publication : 2 avril 2017

Pagination : 174-182

ISBN : 978-2-930953-00-7

ISSN : 2031-4183

Référence électronique

Mélanie Moreas, «Reisverslag. Op zoek naar de misdaden van de rode Khmers: de cambodjaanse herinneringsplekken», Témoigner. Entre histoire et mémoire [Online], 124 | 2017, Online op 30 novembre 2021, geraadpleegd op 01 décembre 2021. URL: http://journals.openedition.org/temoigner/5950 ; DOI: https://doi.org/10.4000/temoigner.5950 


\section{REISVERSLAG}

$\diamond$ Deze rubriek wil inzicht bieden in de soms problematische processen van herinne-
ringsconstructie overal ter wereld. In plaats van te focussen op de gebeurtenissen zelf, onderzoeken auteurs in het Herinneringslabo hoe een collectieve herinnering ontstaat en wordt gecultiveerd, en bestuderen ze de sociopolitieke gevolgen
van het herinneringswerk in een bepaald regio.

Zomer 2016. Na drie weken in Vietnam maak ik per motorboot via de Mekong een lange overtocht naar de Cambodjaanse hoofdstad Phnom Penh. Die verbazingwekkende stad, de dichtstbeft telkens en andere sfer indrukwekkende koninklijk paleis, de geschiedkundige en artheologische mesters ogende zaken en koloniale architecture, getuigenis van Frans Indochina.

Phnom Penh, dat in de jaren 1920 de bijnaam 'de parel van Azie kreeg, is niet alleen een drijvende kracht op economisch en een complexe en bloederige nationale geschiedenis. 1

ijdens de oorlog in Vietnam bood de Canbodjaanse hoofdstad dicon Op 17 april 1975, na vijf jae gevechten. Op 17 apriig lom communisten, trokkende Rode Khmers Penh binnen; de twee miljoca Phnom ven de stad werden snel geëraciers Pin Yathay was een directe getuige. Hij

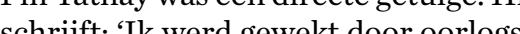
schrijt. "Nk werd gewekt door oorlogsgen' (Pin Yathay 2005, 21, vertarGdH); hij voelde zich 'gespann bevreesd mar opcewonden dat , hij vanactie verlon at de burgeron in thaieve was. Hij vegt eran toe 'Zogls iedereen was ik tegen het corrupte regime

van Lon Nol. ${ }^{3} \mathrm{Ik}$ had niets te vrezen van de Rode Khmers.' Jammer genoeg zouen de Cambodjaanse ingenieur, zijn vrouw, kinderen en alle leden van zijn fantion en 'hropvodingseid, honger, angst warbijéén Cambodjas betekenden,

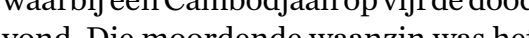
vond. Die moordende waanzin was het de Rode Khmers, die tenupulie door en volledigagraische samenteng ${ }^{4}$

(1) Etnisch dominante groep in Cambodja.

(2) Een gebied samengesteld uit drie actuele landen: (3) Cambodjaans generaal en politicus (1913-1985). (4) Tijdens het bewind van de Rode Khmers waren
bijivoorbeeld scholen en bioscopen gesloten.

\section{OP ZOEK NAAR DE MISDADEN VAN DE RODE KHMERS: \\ DE CAMBODJAANSE HERINNERINGSPLEKKEN}

Een van de bijzonderheden van dit regime was zijn geheimzinnigheid. 'Zodra ze meester waren van het geheimzinnigheid. Zodra ze meester waren van het zich en zelden zelfs het bestann van de corstopten

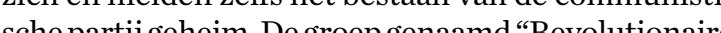
sche partis

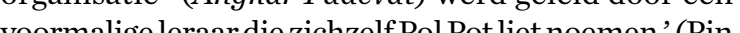
Yathy 2005) Tervill die latste ande Yath macht was, herhaalde hij aldoor: 'Wie zich verzet, is een lijk' D t wa 'bot begin van een zuivering in was het kingslagen, (Bizot 2003), de btavt van de slachtingen in Cambodja.

\section{JULI 2016: BEZOEK AAN DE GEVANGENIS S-215,}

DEN UITEST GEHEMME PLEK

Ditv079), ook bekend als het Tuol (1975-1979), ock bekend als het Tuol Sleng woordigeen herdenkingsplek die elk jar dor en indukwekkend a dic jaar door een in toeristen wor bozocht. Thjens de dictet

(5) De S van santebal (het Khmerwoord voor
veligheid) in combinatie met het nummer van het veiligheid) in combin
veiligheidsradiokanaal

(6) Nederlandse vertaling: vergiftigde heuvel. platen, met bovenop ondoordringbare prikkeldraad stroom

Het begrip 'herdenkingsplek' werd in de jaren tachtig naar voren geschoven door Pierre Nora. Hij chrijft: 'Herdenkingsplekken zijn in de eerste plaat resten. De extreme vorm daarvan eigenlijk, waarb

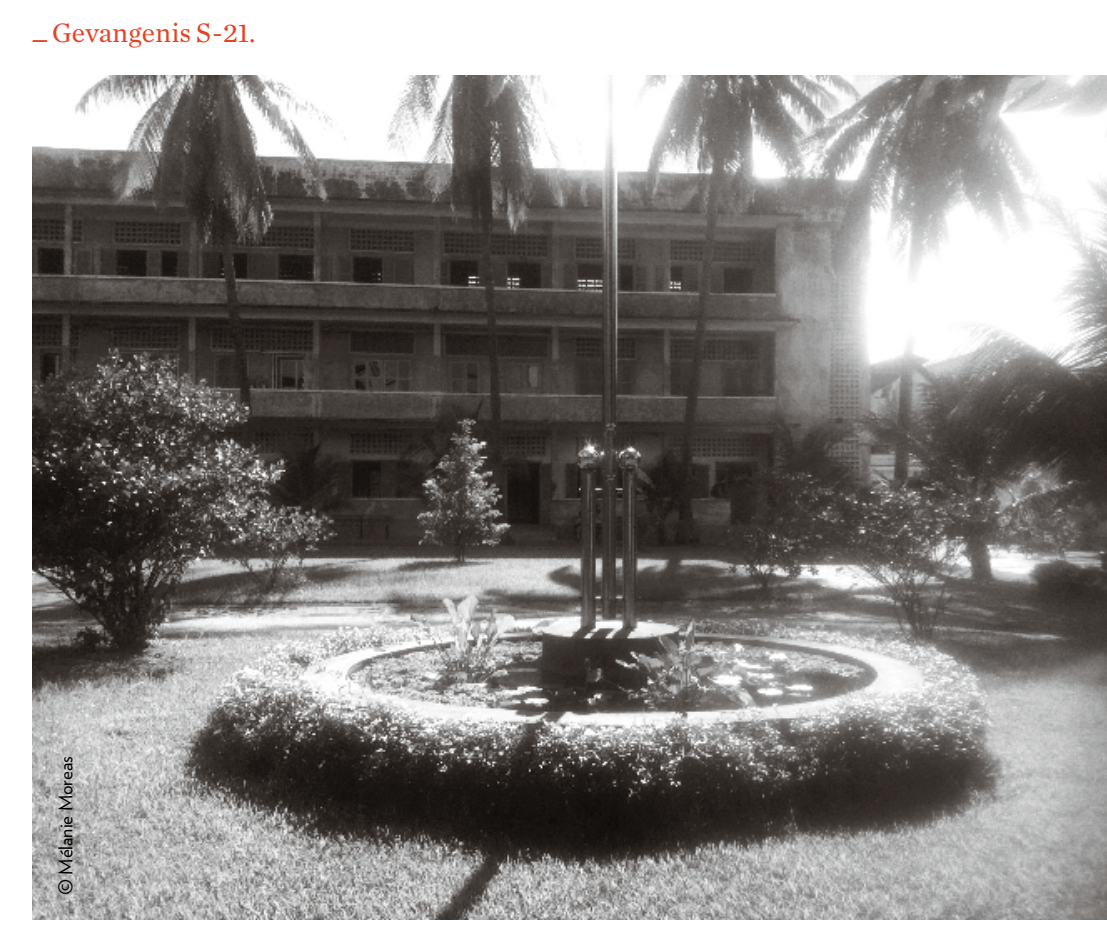




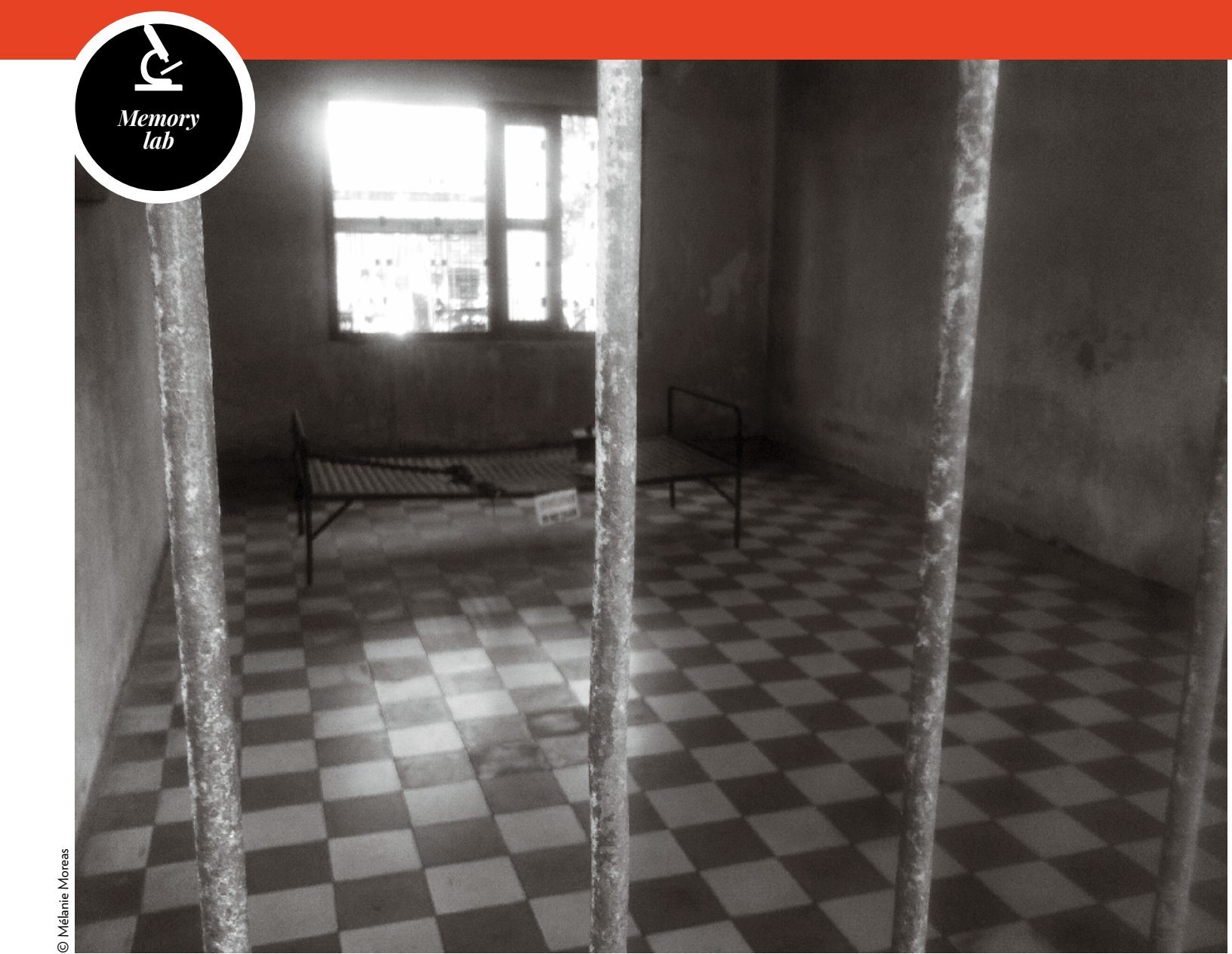

_ Gevangenis S-21, voormalig klaslokaal omgebouwd tot cel.

œ denis die dat bewustzijn interpelleert, omdat het er geen weet van heeft.' (Nora 1997, 28, vertaling GdH) De auteur voegt eraan toe dat een herdenkingsplek, in alle betekenssen van het woord, kan gaan van het meest materièle en concrete object, eventueel op een en ideële object' (ibid). Zodra we onzers zetten in het voormalige geheime centrum S-21 beginzetten in hetvorm te beseffen wat het begrip werkelijk betekent. Eerst en vooral word je door de zachte betekent. Eerst en vooral word je door de zachte en rustige stem van de audiogids uitgenodigd om plaats te nemen op de met bomen omringde banken op het groene plein inhet slachtoffers van het martel- en executiecentrum zijn begraven. Een mooi excuus om te gaan zitten, voor je den en drie dagen heerste in deze voormalige school.?

Er werden tussen de 12000 en 20000 personen opgesloten, inclusief 150 bewakers die beschuldigd waren Slechts twaalf personen overleefden het:

In S-21 interneerden de Rode Khmers alle veronderstelde tegenstanders van het regime, waar ze ook van verdacht werden. De gevangenen waren zowel jongeren als ouderen. Er zaten vrouwen, kinderen en soms hele gezinnen (inclusief baby's) van Cambodjaanse arbeiders, ditectuelen, ministers en diplomaten. Alleen al het feit dat je een bril droeg (zelfs al wasje nog een kind) was volcos

(7) Op deze plek stond de school Tuol Svay Prey (heuvel van de wilde
mangobomen).
Gevangenen werden er's nachts per vrachtwagen heengebracht. In zijn boek Dans l'enfer de Tuol Sleng chifft kunstenar en voormalig gevangene Van Nath:

De bewakers komen terug en voeren ons mee nagr twee Chinese vrachtwagens die met linnen dekzeilen zijn afgedekt. [...] Onze benen moeten in een ketting va tien cent [... Oren dik biewort centine 65 , vertaling $\mathrm{GdH}$ )

Het eigenlijke bezoek begint met een enorm bord waarop de regels staan waaraan de gedetineerden waarop de regels staan waaraan de gedetineerde onder toezicht van de veiligheidsagenten moesten gehoorzamen: 'Hang de idioot niet uit, want jij bent de man die zich tegen de revolutie verzet' en 'Het is veroktroshid terijgt' Vann Nath beschrift hoe of elektroshocks krjet. Vann Nath beschrift hoe ee bewaker van S-21, een jongen van een jaar of vijftie (de jongsten waren tien jaar), de pas aangekomen

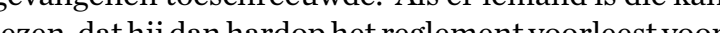
de anderen' (Nath 2008, 76)

GEBOUW A: GRUWELSPOREN

Zo komt de bezoeker in gebouw A met de voorm lige klaslokalen die op de begane grond en de eerste verdieping tot kleine cellen waren 'omgebouwd', met telkens ook traliewerk. De klaslokalen op de tweede verdieping vormden de gemeenschappelijke detentiezalen. Als gevolg van de ondraaglijke, vochtige warm is de lucht bedorven en door de overvloedige inforwatie en de precieze details van de overlevenden ze Via de audiogids verne

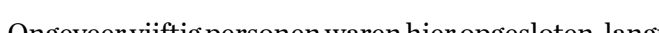
Ongeveer vijtigpersonenwarn op de grond en dicht tegen elkaar aanliggend, de gezinnen bijeen. De voeten van de gevangenen zaten met gietijzeren ringen vast aan lange ijzeren staven. Bij aankom. werden alle gevangenen gefotografeerd, ze werden hier lwam regelmatic de ligsende perm kijken of ze geen pen hadden waarmee ze zelfmoord konden plegen door ze in hun keel te spietsen, of een bout of en. Om halfvijf's ochtends we (Delbrouck \& Vokar 2008)

Vann Nath herinnert zich dat hij slecht sliep, wan de cipiers kwamen onophoudelijk de ketens van de gevangenen controleren uit angst dat ze zouden ontsnappen.

In elk vertrek bevinden zich een materieel spoor, oals een bed, en een foto met een moment uit het dagelijks leven van de gevangenen, bijvoorbeeld de harde ondervragingen, martelingen, ophangingen, gedwonje ook terug in wat Vann Nath schrijft:

Elke dag komen ze gevangenen halen om te ondervragen Voor ze hen wegleiden, doen ze hen handboeien aan en binden een blinddoek voor. Sommigen keren terug met wijnen zonder meer. (Nath 2008, 83)

Het bezoek gaat voort met een halte voor de houten Het bezoek gaat voort met een halte voor dehouten
galg, die met haar lange touw al tijdens de schooltijd dienst deed voor de gymles. Ze werd nooit gebruikt voor terechtstellingen, maar wel voor martelingen. Vanuitz zijn cel kon de schilder Wann Nath die praktijk herhaaldelijk gadeslaan. Later zou hij verduidelijken hem itwe zijn lije werpselen lieten zakken. Als hij bijkwam, werd hij mome

\section{GEBOUW B: EEN PLEK YOOR VORMING EN}

\section{BE}

Na een onderbreking zetten we ons bezoek voort in gebouw B, een ander detentiegebouw. Tegenwoordi staat het in het teken van vorming en behoud van deze herinneringsplek. Beneden hangen honderden foto angevangenen. Onder de slachtoffers bevonden zich niet alleen Cambodjanen, maar ook onder andere Aravertrek, ligt de Briten. Wat verderop, in een ander eav, bijge de 
•. en het hoofd van S-21. Uit verschillende getuigenissen ontstaat een tegenstrijdig beeld van hem, van een heeft Francois Bizot het in zijn boek De poort (2003) over de periode dat hij in de rimboe gevangen (2003) over gehouden en lange gesprekk neerde met Duch', toen zijn leven werd gonar. De Franse auteur stelt dat zijn leven werd gespaard dankij deze beul, die zijn centen koos Uit zijn fiche die werd opgesteld door het Cambodjatribunaal leren we nog het volgende:

Hij zou bij de Rode Khmers zijn gebleven tot begin jaren

zijn vrouw bij een inbraak in 1995 bekeerde hij zich tot

het christendom en vestigde zich in het district Samlaut. Daar woonde hij tot in 1999, toen hij door een journalist (Eend Vervolsens werd hij aanghou Cambodjaanse militaire overheden. (ECCC 2009)

\section{GEKNAKTE LEVENS}

Het bezoek gaat voort, maar in een trager tempo De pas wordt sloom, de geest troebel en onze ziel raakt bevangen door de spoken die ronddwalen over de grond waaronder zoveel leed schuilgaat. Alleen de gebouwen $\mathrm{C}$ en $\mathrm{D}$ blijven nog over. In het eerste bevinden zich individule cllen over houten deutjes. Het twe focus de cever bijvoopde les a

Gevangenis S-21, centrale binnenplaats en gedenksteen

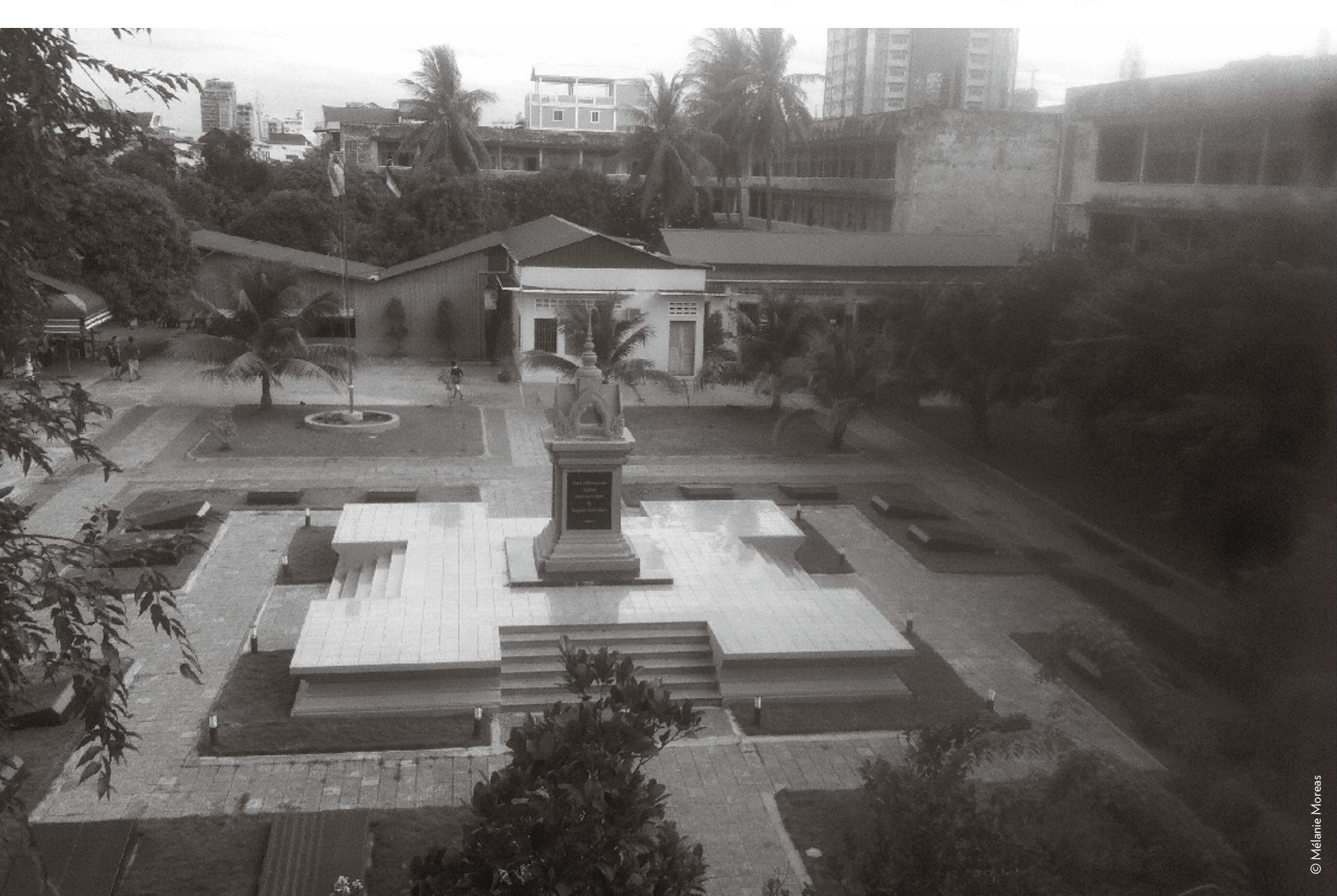

op te geven' (Becker 2012, 82) werd gereconstrueerd door Elizabeth Becker, aan de hand van archieven die deVietnamese troepen ontdekten toen ze het centrum bevrijdden. Tijdens het bewind van Lon Nol werd Bopbevijden. Tijdens het bewnd wan Lon Nol werd Bophana zijn. te zijn. Hoewel ze zwanger was, werd ze verkrach

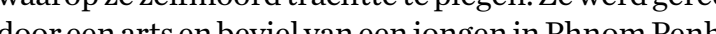

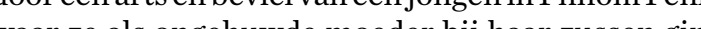
war ze als ongeh re tij in in Ze werden verieft op ent . Ze wen viver de Rode Khy . gebootedorp, war ze trouwde met Sitha, intussen

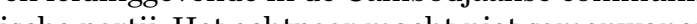
tische partij. Het echtpaar mocht niet samenwonen, want ond hor har als gezinsleven en liefde verboden. Maar Bophan ben a ver gevolg van een slecht verzorgde ziekte ondernam ze ze zich op zelfnor ze zich opnieuw. Een paar maanden later werd haar man aangehouden. Hun brieven werden ontdekt en ook Bophana werd gearresteerd. Ze werd vijf maande langgeinterneerdengemarteld Zet detentiecentrum lich 21.0 25-jarige leeftijd werd ze terechtgesteld. Haa lichaam werdinhet Choeung Ek-Massagraf geworpen, Het bezock is bijna volij.

(angs het centrale plein en de gedenksteen. Er spelen kinderen. op het ritme van hun spel engelach neent het leven weer de overhand. Door de zachte en rustige sten om te audiogids worden we ophieuw uitgenodigd om te gaan zitten op de net bomen omringde banken. De dag loopt ten einde met een smot: een poëdat wordt dat wordt gezongen bij begramiss. In het laatste om de cyclus van leven en dood te aanvarden, zod je het leven met een gerust hart kunt verlaten. Het je het leven met een gerust hart kunt verlaten. Het moeilijk kan begrijpen, want net no beztoek maar de duizen begrijpen, want net nog vertoefde hij bij wreedheid werd doorboord.

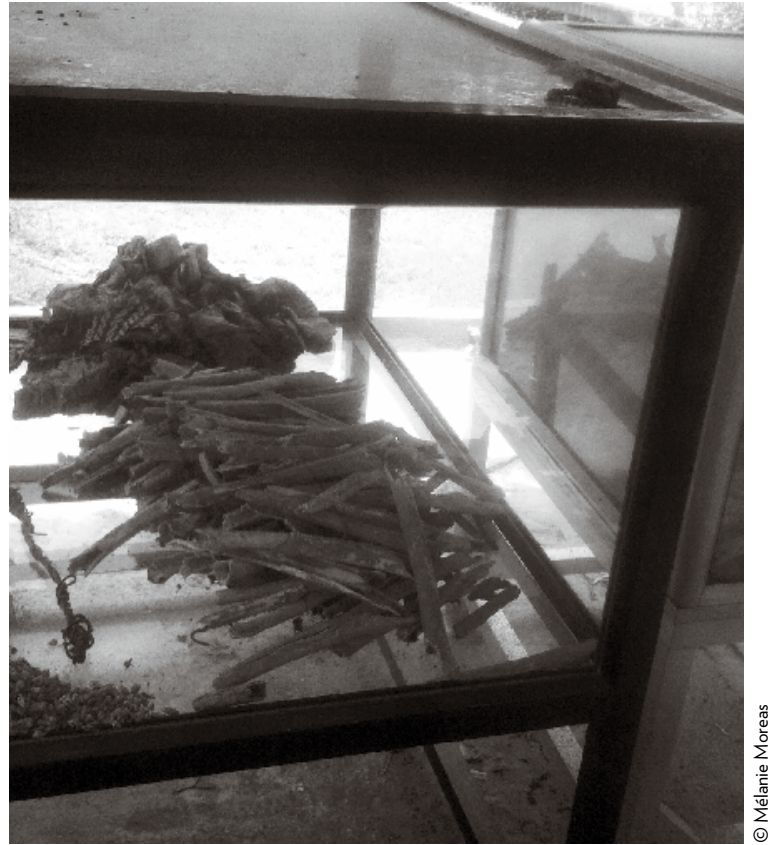

Executieterrein Choeung Ek, menselijke gebeenter

30 JULI 2016: BEZOEK AAN HET MASSAGRAF CHOEUNG EK, EEN EXECUTIETERREIN

Om het belangrijkste massagraf te bereiken, op vijftien kilometer van Phnom Penh, moet je vijfti den. Er zijn driehonderd van dergelijke terne sommige werden pas in 2013 ong Che sommige werden pas in 2013 ontdekt. Choeung E werd ongevormd tot een van 's lands meest promivan meer dan twee hectaren, een voor stig Chine kerkheer dan twee hectaren, een voormalig Chinees de Rode Khmers. Het antal slachtoffers hier wordt de Rode Kh 20000 . antal slachtoffers hier word op meer dan 20000 geschat en er werden duizenden gebeenten teruggevo

Het bezoek verloopt in stilte, met behulp van een audiogids. Opnieuw begeleidt een zachte en rustige stem de bezoeker op een traject dat de logische weg

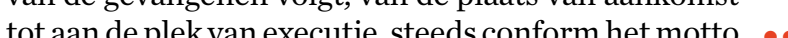




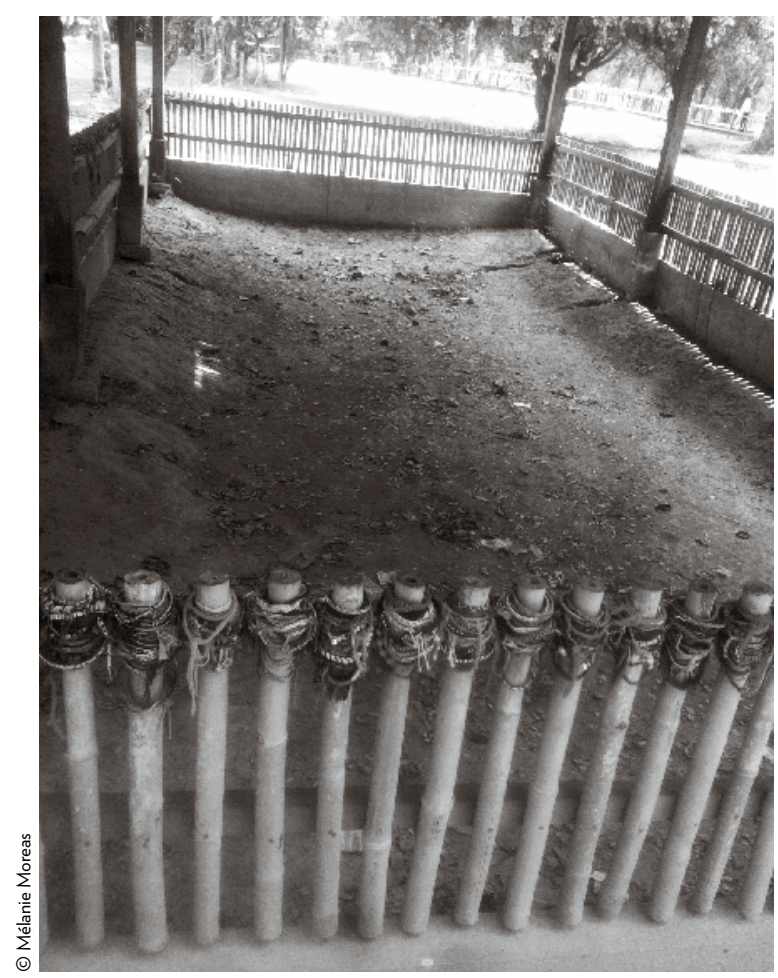

Executieterrein Choeung Ek, een van de massagraven.

.. 'geheimhouding'. De gevangenen kwamen 's nacht per vrachtwagen aan in het kamp, na een rit van dertig ho doekt en geboeid. Ze werden wijsgemaakt dat ze naa en ander detentiecentrum gingen. Gewoonlijk wercedod Onder druk verllikten sommigen hu famili ge vrienden, die in contact zounnigen hun fanille of denden, die in contact zouden staan met de KGB of de CIA, gezworen vijanden van de Rode Khmers. Daarna werden ze aan de rand van de kuil opgewach 'bereleid' door luid gezang om het geschreeuw van bevalid door luid gezang om het geschreeuw van de gevangenen te overstemmen; er werd evenwel nooit Op deze plek bevinden zich 129 lijkkuilen, warin Op deze plek bevinden zich 129 lijkkuilen, waarin baby's van enkele weken oud tot bejaarden. Dergelijke executieplekken worden 'Killing Fields' genoemd. Nu og komen er tijdens het regenseizoen tanden, menselijke resten en kleren van slachtoffers aan de opperakte. De laatste halte is het gedenkteken in de vorm an een boeddhistische stoepa van zeventien ${ }^{8}$ verdiepingen, daarin bevinden zich duizenden beenderen, het materièle bewocidemisdaden platsvo CambodVoorw Voor 列 huidige situtie in Burundi; uit talrijk maar aan de en offiële rapporten op last van de Veilighrtikelen on officièle rapporten op last van de Veiligheidsraad van de David Gakunzi over Burundi:

En de slachtoffers: weerloze lichamen, skeletten met uitstel van executie, toevallig gespaard gebleven, verlam tel van executie, toevallig gespaard gebleven, verlam dor herige schin vor wat ont het war en wanneer kan toeslaan. En die verstikkende lucht, dat gevoe van naderend onhell. ledereen is gekweld, verlamd doo blijven ze hopen niet op voorzienteden, en toch blijven ze hopen, niet op voorzienigheid, maar op een gevoelens kunt hebben. Tegelijkblijveld, waarin je nog gevoelenskunt hebben. Tegelljk bijvenzehopen - als de mensheid het toelaat - dat de genocide onwaarschijnlijk, ongelofellik, onmogelijk magbliken. Versplintering Ontreddering Tote onteddering (Gakunzi 2016)

'NOOIT MEER'?

De zachte stem van de audiogids is niet naief. Ze Delt zeiten am zonder zich te verlezen in melodamatish sentim zont Ze zpreekt niet op medratoon Ze met de uitdruking 'nooit meer!', we in Europa zo val hoit me da we in Europa zo vaak hebben gehoord. Tijdens onze "Nooit min Onzin! Kijk wat er in 1994 in Rwan is gebeurd! Laten we eest de gedachten in is gebenl' houden! (8) Om de intrede te symboliseren van de Rode Khmers in Phnom Penh
op 17 april 1975, het begin van de Cambodjaanse volkerenmoord.
In samenwerking met de Verenigde Naties gingen in 2009 de Extraordinary Chambers in the Courts of Cambodia (ECCC), het Cambodjatribunaal, van start. Ze berechtten verschillende Rode Khmerleiders, onder anderen 'Duch' die op 3 februari 2012 tot levenslange opsluiting werd veroordeeld.

In 2015 herdacht Cambodja de inname van Phnom Penh door de Rode Khmers veertinjane Penh door de Rode Khmers veertigjaar eerder.Er vonChoung van de hudige reging ankere bericht lazen we toen: 'Premier Hun Sen, zelf een voormation wo

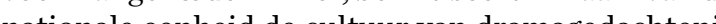
(A) France Presse 2015)

Executieterrein Choeung Ek, schedels tentoongesteld in een boeddhistische stoepa

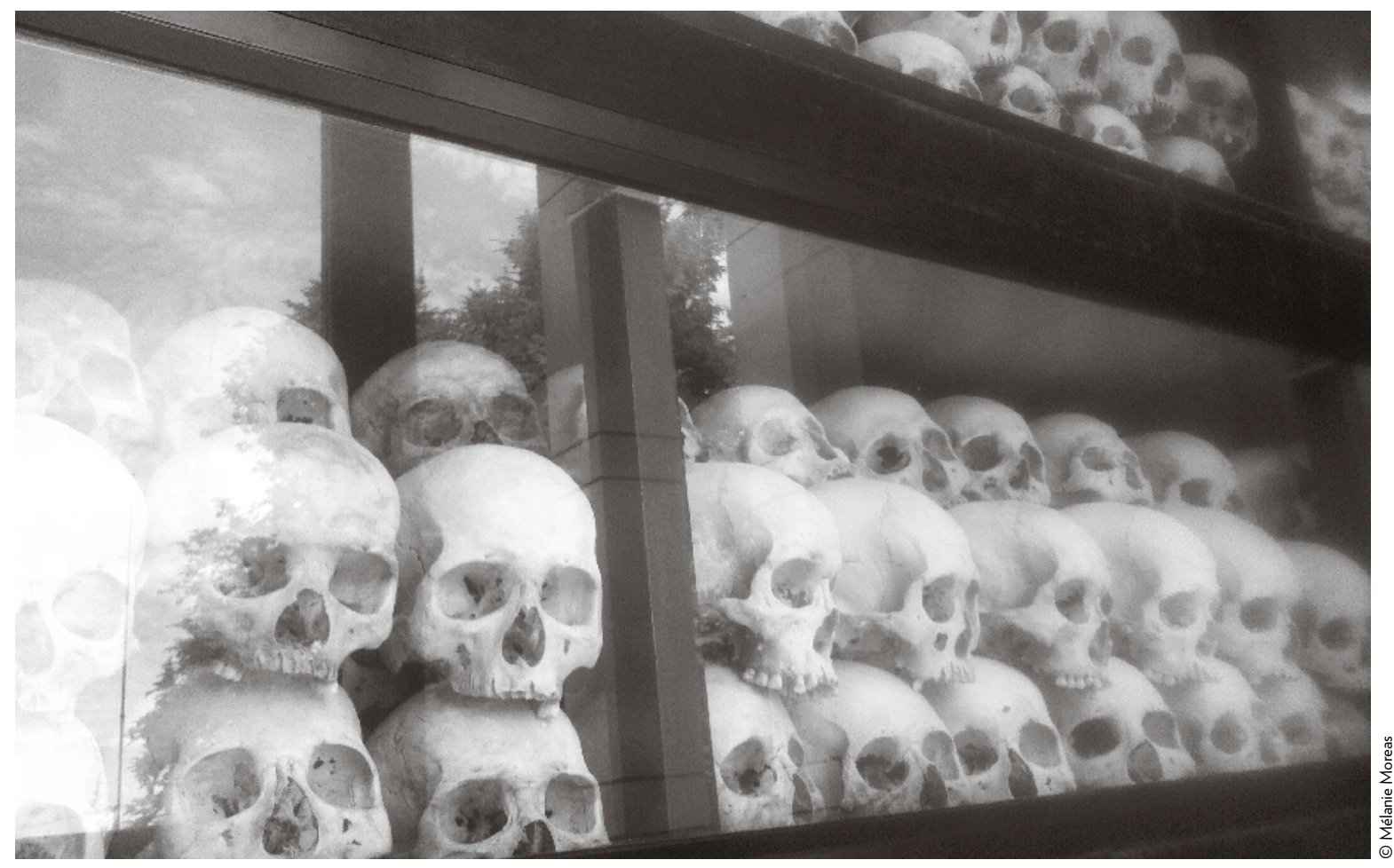
Mélanie Moreas (HEB Defré)
Vertaling uit het Frans: Gorik de Henau

En wat brengt morgen? Veertig jaar is niets. He 作 Z Zols bij de volkerenmord op de Tutsi's in Rwand

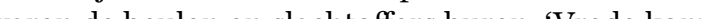
woor gerechtigheid', stelt Margolin, 'mar een vergelijkbare (126) En tot slot, hoewerMoten amnestie enverzoening Met risico op annesie? Of mot je wezenlijk we nken . je het vereden grondig kunt verwerken en nar de toekomst kijken? kelijk het trauma van de uitroeiing te bov, hewer- 


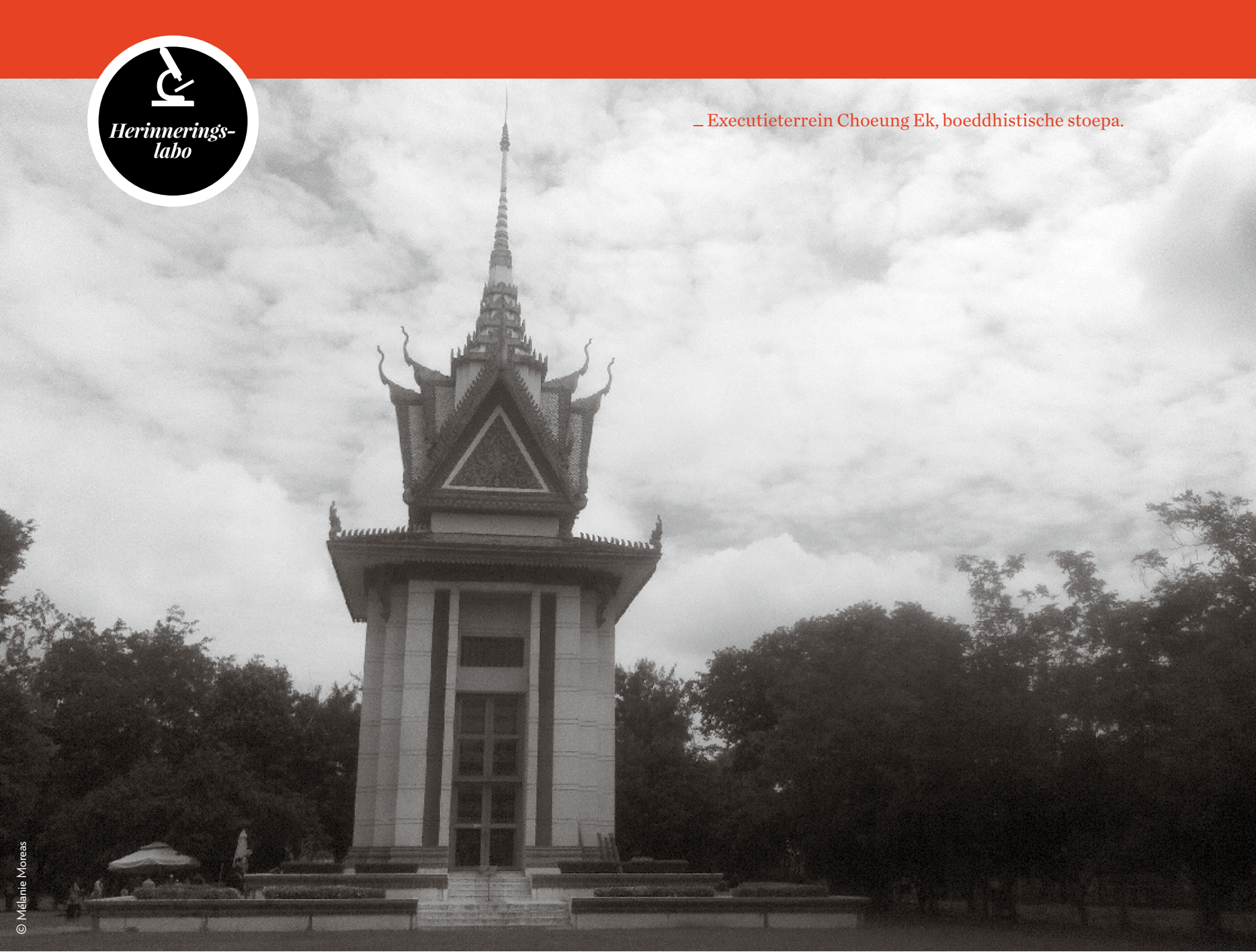

\section{BIBLIOGRAFIE}

- Agence France Presse, Génocide cambodgien: 'll faut que toute la vérité soit faite', Le Point International, 17 april 2015, http://www.lepoint. $\mathrm{fr} / \mathrm{monde} / \mathrm{genocide}$-cambodgien-il-faut-que-toute-la-verite-soitfaite-17-04-2015-1922206_24.ph (geraadpleegd 24 januari 2017).

- Elizabeth Becker, Bophana, L'amour au temps des Khmers rouges, Cambodja: Cambodia Daily Press, 2012.

- François Bizot, De poort [2000], uit het Frans vertaald door Frans van Woerden, Amsterdam: Fagel, 2003.

- Barbara Delbrouck \& Benjamin Vokar, Láaprès génocide au Cambodge, 2008, http://www.apres-genocide-cambodge.com (geraadpleegd 25 januari 2017)

- Extraordinary Chambers in the Courts of Cambodia, 'Kaing Guek Eav', 2009, https://www.eccc.gov.kh/en/indicted-person/kaing-guek-eav (geraadpleegd 23 januari 2017).

- David Gakunzi, 'Burundi, Burundi: dernier appel - ne rien faire, c'est laisser faire', Laregledujeu.org, 30 augustus 2016, http://laregledujeu.org/ 2016/08/30/29766/burundi-burundi-dernier-appel-ne-rien-faire-cestlaisser-faire/ (geraadpleegd 23 januari 2017).

- Ben Kiernan, The Pol Pot Regime: Race, Power and Genocide in Cambodia under the Khmer Rouge, 1975-1979 [1996], New Haven: Yale University Press, 2002.

- Jean-Louis Margolin, À l'extrême du communisme: le génocide cambodgien', in Barbara Lefebvre \& Sophie Ferhadjian (red.),

Comprendre les génocides du $X X^{\circledR}$ siècle, Comparer-Enseigner, Rosnysous-Bois: Bréal, 2007, 108-129.

- Vann Nath, Dans l'enfer de Tuol Sleng. L'inquisition khmere rouge en mots et en tableaux, Bangkok: White Lotus Press, 1998.

- Pierre Nora, Les lieux de mémoire, Parijs: Gallimard, 1997.

- Pin Yathay, Blijf leven, mijn zoon: het schokkende relaas van een overlevende uit de hel van Cambodja [1987], uit het Engels vertaald door Roland Vlek, Amsterdam: Amber, 1988. 